\title{
Stabilization effect of kraft lignin into PBAT:Thermal analyses approach
}

Lara Basilio Tavares $^{1}$, Derval dos Santos Rosa ${ }^{1}$

\author{
${ }^{1}$ Engineering, Modeling and Applied Social Sciences Center, ABC Federal University, Santo André, São Paulo, Brazil. \\ e-mail: dervalrosa@yahoo.com.br, lara.btavares@hotmail.com
}

\begin{abstract}
Sterically hindered phenols are an important class of synthetic antioxidants for polymers, commonly incorporated to inhibit polyolefins or polyesters oxidation. However, synthetic antioxidants use is under restricted regulation due to their potential health risk and environmental impacts. Thus, great interest has been attracted to the phenol-based natural antioxidant such as lignin. This work aimed to evaluate the thermostability of kraft lignin (KL) as a natural antioxidant when incorporated into poly(butylene adipate-co-terephthalate) (PBAT) matrix. PBAT-KL films $(0 \%, 1 \%, 3 \%, 5 \%$ and $10 \%$, by mass) were prepared by twin-screw extrusion followed by thermo-compression. These materials were examined in detail for their effect on the thermal stability using the oxidative induction time (OIT), oxidative induction temperature $\left(\mathrm{OIT}_{\mathrm{emp}}\right)$ and thermogravimetric analysis (TG). According to the results, lignin-containing compositions have improved thermal resistance in oxidative environment, compared to neat PBAT. However, $10 \mathrm{wt} \%$ lignin composition presented the lowest thermostability among lignin-containing compositions. The results showed that kraft lignin promotes the thermal stabilization of PBAT films at the optimal concentration of $1 \%$ by mass.
\end{abstract}

Keywords: Poly(butylene adipate-co-terephthalate), Kraft lignin, Biodegradable polymer, Thermal analysis, Oxidative degradation.

\section{INTRODUCTION}

Lignin is an abundant natural polymer with complex phenolic structure. After cellulose, lignin is the second in abundance among polymers in nature. It can be found in plants, in a proportion of $15 \%$ to $40 \%$ by mass [1]. Lignin is obtained from lignocellulose separation as a by-product, and processes such as paper manufacturing and biofuel production are the largest producers [2]. It is an amorphous, cross-linked and threedimensional phenolic polymer consisting of methoxylated phenylpropane structures [3]. Kraft lignin (KL), a derivative of native lignin, is obtained as a by-product from a pulping process at a large scale [4]. Although the annual lignin extraction in pulp operation around the world is estimated at 60 million [4], the compound is treated as a waste and burned for steam and power generation [6], and less than $2 \%$ is recovered for utilization as a chemical product [2,7]. Lignin is an effective free radical scavenger that stabilizes the reactions induced by oxygen and its radical species. It is not harmful or cytotoxic, biodegradable, environment-friendly, biocompatible [8], which make it a promising material for food packaging and cosmetic applications as an antioxidant [9]. Several studies reported lignin thermal stability effect when incorporated in polyolefins such as polypropylene [10, 11], and biodegradable polymers, including poly(acid lactic) [12, 13] and poly(butylene adipate-co-terephthalate) (PBAT) [14, 15]. Despite few works concerning thermal stability study of lignin into PBAT [14, 16], none of them has a deep investigation focused on the thermal effects of lignin incorporation into PBAT matrix in oxidative atmosphere.

Biodegradable polymers are a potential solution to environmental problems. PBAT is an alternative for packaging applications due to its good processability and biocompatibility, against traditional plastics in which are used for short periods and then discarded [17]. PBAT is a flexible synthetic aliphatic-aromatic copolyester obtained by polycondensation between 1,4-butanediol and a mixture of adipic acid and terephthalic acid [18]. It features good thermal and mechanical properties [19], including comparable tensile properties to those of low-density polyethylene.

The objective of this study was to evaluate the thermostability of kraft lignin as a natural antioxidant when incorporated into PBAT matrix, using different thermal analysis methods including oxidation induction time (OIT), oxidation induction temperature $\left(\mathrm{OIT}_{\mathrm{emp}}\right)$ and thermogravimetric $(\mathrm{TG})$ analysis. 


\section{MATERIALS AND METHODS}

\subsection{Materials}

Kraft lignin (KL) was supplied by Suzano Papel \& Celulose, Brazil; obtained as a by-product from pulp and paper manufacturing (brown color; $\mathrm{pH} 3.8$; $95 \%$ solid content; $2 \%$ ash content). Poly(butylene adipate-coterephthalate) (PBAT) was supplied by BASF Brazil under the trade name Ecoflex ${ }^{\circledR} \mathrm{F}$ Blend C1200 (mass density $1.26 \mathrm{~g} . \mathrm{cm}^{-3}$ at $23{ }^{\circ} \mathrm{C}$; melt rate flow $3.3 \mathrm{~g} .10 \mathrm{~min}^{-1}$ at $190{ }^{\circ} \mathrm{C}, 2.16 \mathrm{~kg}$; melting point $115^{\circ} \mathrm{C}$ ).

\subsection{PBAT and PBAT-KL films preparation}

Kraft lignin and PBAT were dried at $80{ }^{\circ} \mathrm{C}$ and $60{ }^{\circ} \mathrm{C}$, respectively, for 24 h before use. KL $(0 \%, 1 \%, 3 \%$, $5 \%$ and $10 \%$ by mass) was incorporated into PBAT by a twin-screw extruder (THERMO HAAKE Minilab Rheomex, model CTW5) under temperature profile of 132, 135, 135, 138, 138 and $140^{\circ} \mathrm{C}$ from the feeder to the die and $60 \mathrm{rpm}$. After extrusion, samples were thermo-compressed under a heating press $\left(140^{\circ} \mathrm{C}, 1.5\right.$ ton, $90 \mathrm{~s}$ ) between two poly(tetrafluoroethylene) (PTFE) sheets and a steel mold of $1.5 \mathrm{~mm}$. Table 1 summarizes the compositions.

Table 1: PBAT and kraft lignin (KL) compositions under study.

\begin{tabular}{c|c|c}
\hline CODE & PBAT (\%) & KL (\%) \\
\hline PBAT_L0 & 100 & 0 \\
\hline PBAT_L1 & 99 & 1 \\
\hline PBAT_L3 & 97 & 3 \\
\hline PBAT_L5 & 95 & 5 \\
\hline PBAT_L10 & 90 & 10 \\
\hline
\end{tabular}

\subsection{PBAT and PBAT-KL films characterization}

\subsubsection{Oxygen induction time (OIT)}

OIT is an accelerated test to assess the oxidation stability of polymers, where samples are exposed to an oxidant atmosphere at an elevated and constant temperature (above melting temperature), in order to verify the time needed for their oxidation occur by varying the heat flow. Measurements were carried out based on ASTM D3895-14 [20], using DSC Q-200 equipment (TA Instruments). Samples of 5.5 $\pm 0.5 \mathrm{mg}$ were heated in a nitrogen atmosphere until $220^{\circ} \mathrm{C}$. After 5 minutes of isotherm at $220^{\circ} \mathrm{C}$, the nitrogen atmosphere was switched to oxygen (both at $50 \mathrm{~mL} \cdot \mathrm{min}^{-1}$ ) and then the temperature was held for 120 minutes or until the peak of DSC curves appeared. Aluminium pans were used without any cover. All samples were measured in duplicate.

\subsubsection{Oxygen induction temperature (OIT $\mathrm{emp}_{\mathrm{e}}$}

Samples were characterized with respect to the energy released during the oxidation reactions using the same equipment described in 2.3.1. The samples were subjected to heating from 35 to $300{ }^{\circ} \mathrm{C}$ in an oxygen atmosphere $\left(50 \mathrm{~mL} \cdot \mathrm{min}^{-1}\right)$ at a heating rate of $10{ }^{\circ} \mathrm{C} \cdot \mathrm{min}^{-1}$. The samples have an average mass of $5.5 \pm 0.5 \mathrm{mg}$ and measurements were carried out in duplicate. Aluminium pans were used without any cover.

\subsubsection{Thermogravimetric analysis (TG)}

The thermogravimetric characterization of the samples was performed on a Netzsch equipment model STA $449 \mathrm{~F} 3$, the average mass of $20.0 \pm 0.5 \mathrm{mg}$ and subjected to heating up to $500{ }^{\circ} \mathrm{C}$ at a heating rate of 10 ${ }^{\circ} \mathrm{C} . \mathrm{min}^{-1}$ under an oxygen atmosphere $\left(50 \mathrm{~mL} \cdot \mathrm{min}^{-1}\right)$. All measurements were made in duplicate.

\section{RESULTS AND DISCUSSION}

Table 2 presents the OIT results for neat PBAT and PBAT-lignin compositions. According to the results, oxidative peak time was recorded at $6 \mathrm{~min}$ for neat PBAT, at $220^{\circ} \mathrm{C}$. The lignin addition has improved the 
thermo-oxidative resistance. Compositions of $1 \mathrm{wt} \%, 3 \mathrm{wt} \%$ and $5 \mathrm{wt} \%$ lignin-containing did not show an exothermic peak, indicating these compositions are more effective to withstand heat and oxygen. However, PBAT_L10 presented an oxidative peak at $31 \mathrm{~min}$, suggesting that $10 \mathrm{wt} \%$ of lignin addition reduce the thermostability in comparison to other lignin-containing samples.

Table 2: Oxidative induction time results for neat PBAT and PBAT-KL compositions at $220^{\circ} \mathrm{C}$.

\begin{tabular}{c|c}
\hline SAMPLE & TIME (MIN) \\
\hline PBAT_L0 & 6 \\
\hline PBAT_L1 & $>120$ \\
\hline PBAT_L3 & $>120$ \\
\hline PBAT_L5 & $>120$ \\
\hline PBAT_L10 & 31 \\
\hline
\end{tabular}

For a better understanding of kraft lignin efficiency as an antioxidant, oxidative induction temperature $\left(\mathrm{OIT}_{\mathrm{emp}}\right)$ or dynamic OIT [21] was conducted. In this method, no gases change at a defined time or isotherm are employed. The samples are heated continuously under oxygen atmosphere up to an exothermic peak. Fig.

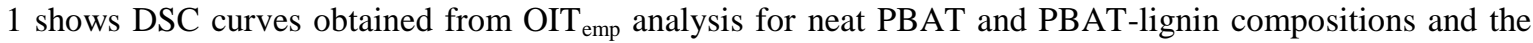
average results for the extrapolated onset temperatures are described in Table 3. A similar trend was found when compared to OIT analysis. The beginning of oxidative reactions for lignin-containing compositions occurs at higher temperatures than for neat PBAT $\left(214^{\circ} \mathrm{C}\right)$, indicating that lignin addition exhibit higher thermostability. Once again, PBAT_L10 presented the lowest oxidative temperature among lignin-containing compositions, $222^{\circ} \mathrm{C}$, and PBAT_L1 presented the highest oxidative temperature, $299^{\circ} \mathrm{C}$.

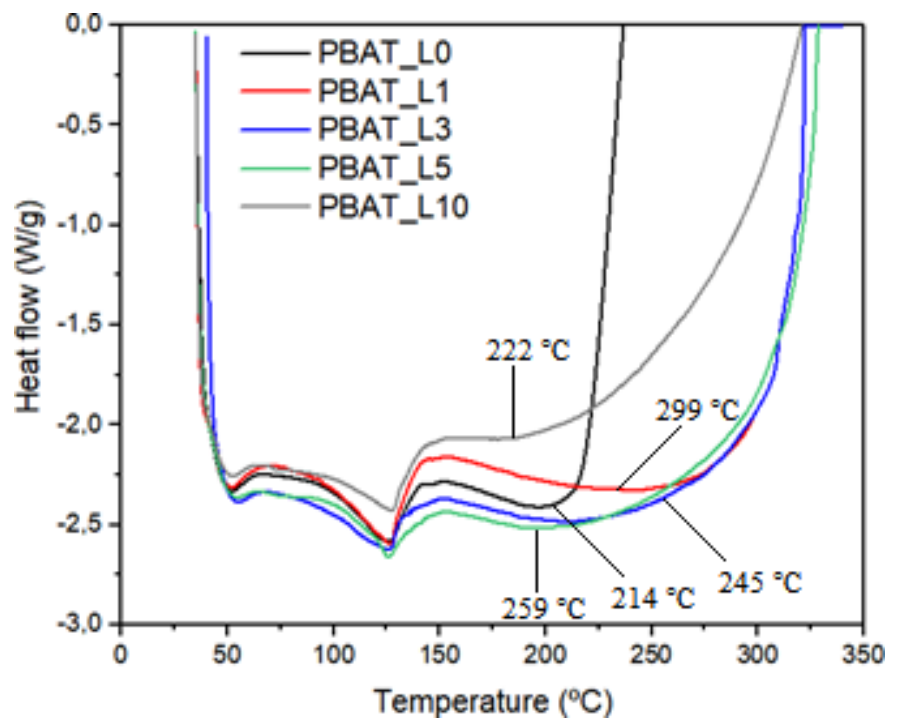

Figure 1: Oxidative induction temperature curves for neat PBAT and PBAT-KL compositions. 
Table 3: Onset oxidative induction temperature results for neat PBAT and PBAT-KL compositions.

\begin{tabular}{c|c}
\hline SAMPLE & $\begin{array}{c}\text { ONSET } \\
\text { TEMPERATURE } \\
\text { (्) })\end{array}$ \\
\hline PBAT_L0 & 214 \\
\hline PBAT_L1 & 299 \\
\hline PBAT_L3 & 245 \\
\hline PBAT_L5 & 259 \\
\hline PBAT_L10 & 222 \\
\hline
\end{tabular}

The antioxidant activity of lignin was confirmed by thermogravimetric analysis in an oxidative atmosphere. Table 4 summarizes the initial degradation temperature considered at $10 \%$ mass loss $\left(\mathrm{T}_{10 \%}\right)$, and the temperature at the maximum degradation rate $\left(\mathrm{T}_{\mathrm{MAX}}\right)$, determined by the maximum value of the first derivative (DTG), for neat PBAT and PBAT-lignin compositions. TG and DTG curves are shown in Fig. 2. All TG curves exhibit one single degradation step (Fig. 2a), as similarly reported by Xing et al. [14]. The lignin addition increased the $\mathrm{T}_{10 \%}$ of neat PBAT, suggesting that KL incorporation inhibit oxidation. PBAT_L0 presented $\mathrm{T}_{10 \%}$ at $339^{\circ} \mathrm{C}$, followed by PBAT_L10 at $360^{\circ} \mathrm{C}$. For compositions of 1,3 and $5 \mathrm{wt} \%$ lignin, they did not exhibit significant variation, in which the composition PBAT_L1 was the most thermostable. However, as degradation takes place at higher temperatures, there is no significant difference between samples, as observed from DTG curves (Fig. 2b).
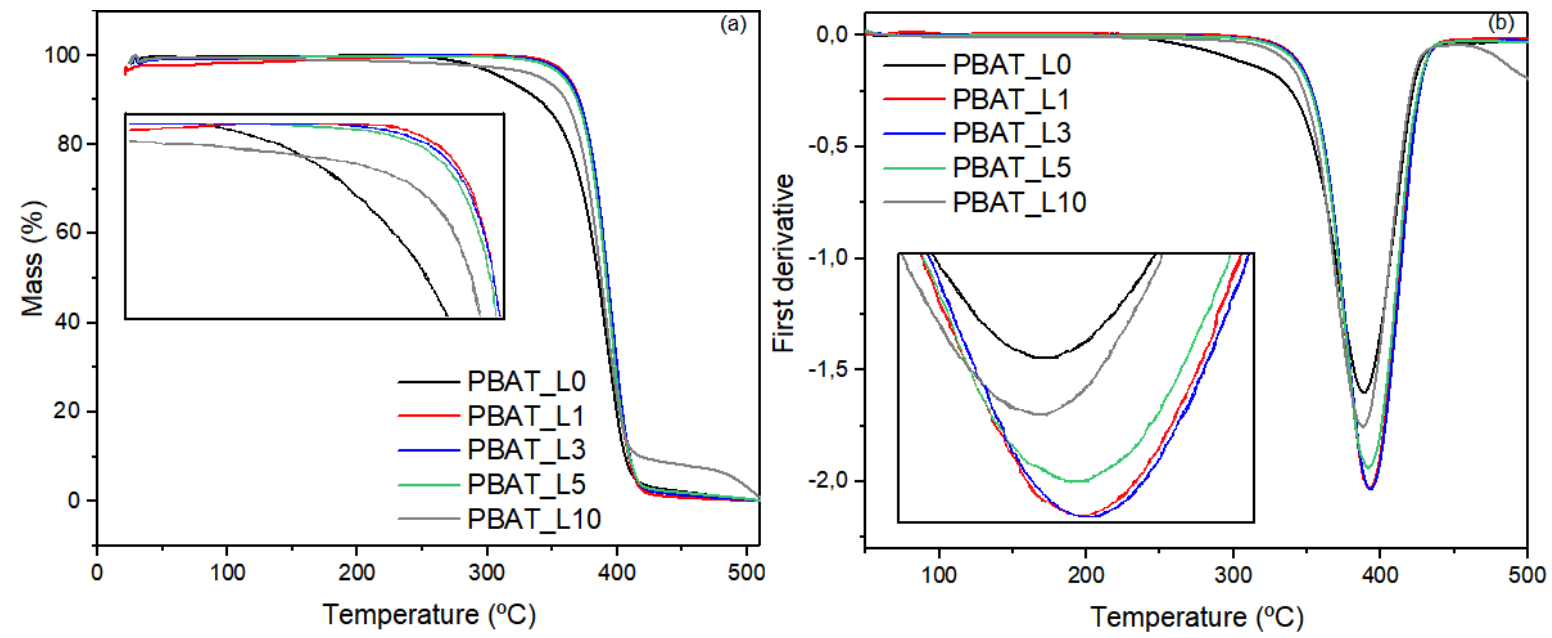

Figure 2: (a) TG and (b) DTG curves for neat PBAT and PBAT-KL compositions.

Table 4: Onset oxidative induction temperature results for neat PBAT and PBAT-KL compositions.

\begin{tabular}{c|c|c}
\hline SAMPLE & $\mathbf{T}_{\mathbf{1 0} \%}\left({ }^{\circ} \mathbf{C}\right)$ & $\mathbf{T}_{\mathbf{M A X}}\left({ }^{\circ} \mathbf{C}\right)$ \\
\hline PBAT_L0 & 339 & 388 \\
\hline PBAT_L1 & 371 & 392 \\
\hline PBAT_L3 & 370 & 393 \\
\hline PBAT_L5 & 368 & 391 \\
\hline PBAT_L10 & 360 & 388 \\
\hline
\end{tabular}


Our previous work [4] reported that $10 \mathrm{wt} \%$ lignin addition into PBAT matrix caused particles agglomeration and consequently phase separation, indicated by atomic force modulation (AFM) analysis. According to the results, KL incorporation has increased storage modulus (E') in comparison to neat PBAT. However, $10 \mathrm{wt} \% \mathrm{KL}$ addition has the lowest E' result among lignin-containing compositions, due to lignin agglomeration. This effect might justify the lower thermostability presented for PBAT_L10 herein. Other work also reported lignin agglomeration in PBAT matrix for concentration up to $10 \mathrm{wt} \%$ [14]. The authors noticed microvoids in the sample, due to phase separation.

\section{CONCLUSIONS}

Kraft lignin was used as biobased antioxidant for biodegradable polymer PBAT. The lignin addition increased the oxidation induction time, oxidative degradation and thermal degradation temperatures of the matrix. Kraft lignin promotes the thermal stabilization of PBAT films at the optimal concentration of $1 \%$ by mass. However, the thermo stabilization effect for the composition of $10 \mathrm{wt} \% \mathrm{KL}$ was the lowest among lignin-containing compositions, probably because of lignin phase separation.

\section{AKNOWLEGMENTS}

The authors acknowledge UFABC and CAPES for financial support.

\section{BIBLIOGRAPHY}

[1] GELlERSTEDT, G., HENRIKSSON, G., "Lignins: Major sources, structure and properties", In: Belgacem, M.N., Gandini, A. (eds), Monomers, Polymers and Composites from Renewable Resources, 1 ed., chapter 9, Oxford, United Kingdom, Elsevier, 2008.

[2] LORA, J., "Industrial commercial lignins: Sources, properties and applications", In: Belgacem, M.N., Gandini, A. (eds), Monomers, Polymers and Composites from Renewable Resources, 1 ed., chapter 10, Oxford, United Kingdom, Elsevier, 2008.

[3] LEE, A., DEN, Y., "Green polyurethane from lignin and soybean oil through non-isocyanate reactions", European Polymer Journal, v. 63, pp. 67-73, Feb. 2015.

[4] TAVARES, L.B., ITO, N.M., SALVADORI, M.C., et al., "PBAT/kraft lignin blend in flexible laminated food packaging: Peeling resistance and thermal degradability", Polymer Testing, v. 67, pp. 169-176, May 2018.

[5] YE, D., LI, S., LU, X., et al., "Antioxidant and thermal stabilization of polypropylene by addition of butylated lignin at low loadings", ACS Sustainable Chemistry and Engineering, v. 4, n. 10, pp. 5248-5257, Jul. 2017.

[6] GARCÍA, A., TOLEDANO, A., ANDRÉS, M.A., et al., "Study of the antioxidante capacity of Miscanthus sinensis lignins”, Process Biochemistry, v. 45, n. 6, pp. 935-940, Jun. 2010.

[7] ARSHANITSA, A., PONOMARENKO, J., DIZHBITE, T., et al., "Fractionation of technical lignins as a tool for improvement of their antioxidant properties", Journal of Analytical and Applied Pirolysis, v. 103, pp. 78-85, Sep. 2013.

[8] GE, Y., WEI, Q., LI, Z., "Preparation and evaluation of the free radical scavenging activities of nanoscale lignin biomaterials", BioResources, v. 9, n. 4, pp. 6699-6706, 2014.

[9] MORSElla, M., D’AlESSANDRO, N., LANTERNA, A.E., et al., "Improving the Sunscreen Properties of TiO2through an Understanding of Its Catalytic Properties", ACS Omega, v.1, pp. 464-469, Sep. 2016.

[10] GADIOLI, R., WALDMAN, W.R., DE PAOLI, M.A., "Lignin as a green primary antioxidant for polypropylene”, Journal of Applied Polymer Science, v. 133, n. 45, pp. 1-7, Mar. 2016.

[11] BLANCO, I., CICALA, G., LATTERI, A., et al., "Thermal characterization of a series of lignin-based polypropylene blends", Journal of Thermal Analysis and Calorimetry, v. 127, n. 1, pp. 147-153, Jan. 2017.

[12] SHANKAR, S., RHIM, J.W., WON, K., "Preparation of poly(lactide)/lignin/silver nanoparticles composite films with UV light barrier and antibacterial properties", International Journal of Biological Macromolecules, v. 107, pp. 1724-1731, Feb. 2018. 
[13] CICALA, G., SACCULlO, G., BLANCO, I., et al., "Polylactide/lignin blends: Effects of processing conditions on structure and thermo-mechanical properties", Journal of Thermal Analysis and Calorimetry, v. 130, n. 1, pp. 515-524, Oct. 2017.

[14] XING, Q., RUCH, D., DUBOIS, P., et al., "Biodegradable and High-Performance Poly(butylene adipate-co-terephthalate)-Lignin UV-Blocking Films", ACS Sustainable Chemistry and Engineering, v. 5, n. 11, pp. 10342-10351, Sep. 2017.

[15] XING, Q., BUONO, P., RUCH, D., et al, "Biodegradable UV-Blocking Films through Core-Shell Lignin-Melanin Nanoparticles in Poly(butylene adipate-co-terephthalate)" , ACS Sustainable Chemistry and Engineering, v. 7, n. 4, pp. 4147-4157, Sep. 2019.

[16] CHEN, R., ABDELWAHAB, M. A., MISRA, M., et al., "Biobased ternary blends of lignin, poly(lactic acid), and poly(butylene adipate-co-terephthalate): The effect of lignin heterogeneity on blend morphology and compatibility", Journal of Polymers and the Environment, v. 22, pp. 439-448, Oct. 2014.

[17] SANGRONIZ, A., GONZALEZ, A., MARTIN, L., et al., "Miscibility and degradation of polymer blends based on biodegradable poly(butylene adipate-co-terephthalate)", Polymer Degradation and Stability, v. 151, pp. 25-35, May 2018.

[18] LAYCOCK, B., NIKOLIC, M., COLWELL, J.M, et al., "Lifetime prediction of biodegradable polymers", Progress in Polymer Science, v. 71, pp. 144-189, Aug. 2017.

[19] VROMAN, I., TIGHZERT, L., “Biodegradable polymers”, Materials (Basel), v. 2, n. 2, pp. 307-344, Jun. 2009.

[20] ASTM D3895 "Standard Test Method for Oxidative-Induction Time of Polyolefins by Differential Scanning Calorimetry”, ASTM International Standard, 2014.

[21] FITARONI, L.B., DE LIMA, J.A., CRUZ, S.A., et al., "Thermal stability of polypropylenemontmorillonite clay nanocomposites: Limitation of the thermogravimetric analysis", Polymer Degradation and Stability, v. 111, pp. 102-108, Jan. 2015.

\section{ORCID}

Derval dos Santos Rosa https://orcid.org/0000-0001-9470-0638

Lara Basilio Tavares http://orcid.org/0000-0001-7316-0388 